\title{
Consumption Responses to Temporary Tax Incentives: Evidence from State Sales Tax Holidays
}

\section{Online Appendix}

\author{
Sumit Agarwal \\ Georgetown University, ushakri@yahoo.com \\ Nathan Marwell \\ University of Wisconsin, marwell@wisc.edu \\ Leslie McGranahan \\ Federal Reserve Bank of Chicago, leslie.mcgranahan@chi.frb.org
}

\section{A Model of the Consumption Response to Temporary Price Changes}

\subsection{Model Setup}

While one may expect that consumption should increase during a period when prices are temporarily lowered, it is not obvious how consumers should behave before and after such a price change. A price change has two first order effects: a wealth effect and a substitution effect. If consumers are forward looking and can smooth consumption across time, then depending on the magnitudes of these effects we may expect to see consumers increase or decrease consumption before the price change.

We introduce a simple model of consumption surrounding a temporary price change. Consumers are forward looking and solve the following utility maximization problem:

$$
\begin{array}{ccc}
u\left(c_{1}\right)+\beta \cdot u\left(C_{2}\right) & +\beta^{2} \cdot u\left(C_{3}\right) & \text { s.t. } \\
p_{1} \cdot c_{1}+s_{1} & = & y \\
p_{2} \cdot c_{2}+s_{2} & = & y+R \cdot s_{1} \\
p_{3} \cdot c_{3} & = & y+R \cdot s_{2} \\
c_{2}+(1-\delta) \cdot c_{1} & = & C_{2} \\
c_{3}+(1-\delta) \cdot C_{2} & = & C_{3}
\end{array}
$$

The model has the following features. Consumers live for three periods. In each period, consumers receive income $y$, and must decide how to allocate this income between consumption 
and savings. Savings net a gross return $R$ each period and consumption is durable with a depreciation rate $\delta$ each period. Consumers maximize the sum of each period's discounted utility subject to per-period budget constraints, which are linked across periods by the savings and consumption depreciation laws of motion.

To make the model tractable, we use a standard parameterization for utility:

$$
u(c)=\frac{c^{1-\frac{1}{\sigma}}}{1-\frac{1}{\sigma}}
$$

where $\sigma$ is the intertemporal elasticity of substitution (IES).

To solve the model, we take the first order conditions with respect to the savings in period 1 and 2 :

$$
\begin{array}{ll}
\operatorname{FOC}\left(\mathrm{s}_{1}\right): & u^{\prime}\left(c_{1}\right)=\frac{\beta\left(p_{1} r-(1-\delta) p_{2}\right)}{p_{2}} \cdot\left(\beta \delta u^{\prime}\left(C_{3}\right)+u^{\prime}\left(C_{2}\right)\right) \\
\operatorname{FOC}\left(\mathrm{s}_{2}\right): & u^{\prime}\left(C_{2}\right)=\frac{\beta\left(p_{2} r-(1-\delta) p_{3}\right)}{p_{3}} \cdot u^{\prime}\left(C_{3}\right)
\end{array}
$$

Simplifying further yields

$$
u^{\prime}\left(c_{1}\right)=u^{\prime}\left(C_{2}\right) \frac{\beta r\left(p_{1} r-(1-\delta) p_{2}\right)}{p_{2} r-(1-\delta) p_{3}}
$$

Using the CES utility function, we can solve for $C_{2}$ and $C_{3}$ :

$$
\begin{aligned}
& C_{2}=c_{1}\left(\frac{\beta r\left(p_{1} r-(1-\delta) p_{2}\right)}{p_{2} r-(1-\delta) p_{3}}\right)^{\sigma} \\
& C_{3}=c_{1}\left(\frac{\beta^{2} r\left(p_{1} r-(1-\delta) p_{2}\right)}{p_{3}}\right)^{\sigma}
\end{aligned}
$$

Now, using the law of motion for $C_{2}$ and $C_{3}$, we can solve for $c_{2}$ and $c_{3}$ in terms of $c_{1}$ : 


$$
\begin{aligned}
& c_{2}=c_{1}\left(\left(\frac{\beta r\left(p_{1} r-(1-\delta) p_{2}\right)}{p_{2} r-(1-\delta) p_{3}}\right)^{\sigma}-\delta\right) \\
& c_{3}=c_{1}\left(\left(\frac{\beta\left(p_{2} r-(1-\delta) p_{3}\right)}{p_{3}}\right)^{\sigma}-\delta\right)\left(\frac{\beta r\left(p_{1} r-(1-\delta) p_{2}\right)}{p_{2} r-(1-\delta) p_{3}}\right)^{\sigma}
\end{aligned}
$$

Lastly, we rearrange the intertemporal budget constraint:

$$
c_{1} p_{1} r^{2}+c_{2} p_{2} r+c_{3} p_{3}=y\left(1+r+r^{2}\right)
$$

Thus, we have three equations and three unknowns and can proceed to solve for $c_{1}, c_{2}$ and $c_{3}$

\subsection{Baseline results}

For ease of notation, we define $Y=\frac{y\left(1+r+r^{2}\right)}{p}$. In the baseline case, prices in all periods are equal:

$$
p_{1}, p_{2}, p_{3}=p
$$

Plugging in prices, we solve for consumption in all periods:

$$
\begin{aligned}
& c_{1}=\frac{Y}{r^{2}+(\beta r)^{\sigma}\left(\beta(r-(1-\delta))^{\sigma}-(1-\delta)\right)+r\left((\beta r)^{\sigma}-(1-\delta)\right)} \\
& c_{2}=\frac{Y\left((\beta r)^{\sigma}-(1-\delta)\right)}{r^{2}+(\beta r)^{\sigma}\left(\beta(r-(1-\delta))^{\sigma}-(1-\delta)\right)+r\left((\beta r)^{\sigma}-(1-\delta)\right)} \\
& c_{3}=\frac{Y(\beta r)^{\sigma}\left((\beta(r-(1-\delta)))^{\sigma}-(1-\delta)\right)}{r^{2}+(\beta r)^{\sigma}\left(\beta(r-(1-\delta))^{\sigma}-(1-\delta)\right)+r\left((\beta r)^{\sigma}-(1-\delta)\right)}
\end{aligned}
$$




\section{$1.3 \mathrm{STH}$ case}

In the $\mathrm{STH}$, the price in the middle period is less than in the periods before and after:

$$
p_{1}, p_{3}=p, p_{2}=\alpha p, \alpha<1
$$

This yields:

$$
\begin{aligned}
& \tilde{c}_{1}=\frac{Y}{r^{2}+\left(\beta(\alpha r-(1-\delta))^{\sigma}-(1-\delta)\right)\left(\frac{\beta r(r-\alpha(1-\delta))}{\alpha r-(1-\delta)}\right)^{\sigma}+\alpha r\left(\left(\frac{\beta r(r-\alpha(1-\delta)}{\alpha r-(1-\delta)}\right)^{\sigma}-(1-\delta)\right)} \\
& \tilde{c}_{2}=\frac{Y\left(\left(\frac{\beta r(r-\alpha(1-\delta))}{\alpha r-(1-\delta)}\right)^{\sigma}-(1-\delta)\right)}{r^{2}+\left(\beta(\alpha r-(1-\delta))^{\sigma}-(1-\delta)\right)\left(\frac{\beta r(r-\alpha(1-\delta))}{\alpha r-(1-\delta)}\right)^{\sigma}+\alpha r\left(\left(\frac{\beta r(r-\alpha(1-\delta)}{\alpha r-(1-\delta)}\right)^{\sigma}-(1-\delta)\right)} \\
& \tilde{c}_{3}=\frac{Y\left(\beta(\alpha r-(1-\delta))^{\sigma}-(1-\delta)\right)\left(\frac{\beta r(r-\alpha(1-\delta))}{\alpha r-(1-\delta)}\right)^{\sigma}}{r^{2}+\left(\beta(\alpha r-(1-\delta))^{\sigma}-(1-\delta)\right)\left(\frac{\beta r(r-\alpha(1-\delta))}{\alpha r-(1-\delta)}\right)^{\sigma}+\alpha r\left(\left(\frac{\beta r(r-\alpha(1-\delta)}{\alpha r-(1-\delta)}\right)^{\sigma}-(1-\delta)\right)}
\end{aligned}
$$

\subsection{Effects of the STH}

Having solved for consumption in all three periods, we know can evaluate the effects of the STH. However, given the number of parameters and functional form of consumption it is not feasible to find an analytic solution for the conditions under which consumption may increase or decrease under a STH. So, we use the following computational approach. For any value of $\beta, \alpha$, and $r^{1}$, we solve for $\tilde{c}_{0}(\sigma, \delta)-c_{0}(\sigma, \delta)$ for all feasible values of $\sigma, \delta$. We then partition the set $\{\delta, \sigma\}$ by whether this difference is positive or negative. We then do the same thing only over all feasible values for $\beta, \alpha$, and $r$.

Our main finding is that for all feasible values of the parameter space, we find a sets of $\{\delta, \sigma\}$ where consumption either increase or decreases during a STH for the periods 1 and 3. However, consumption only increases during a STH.

For example, below is a graph of consumption for the period before the STH (period 1):

\footnotetext{
${ }^{1}$ Since $Y$ enters consumption linearly, it nets out.
} 


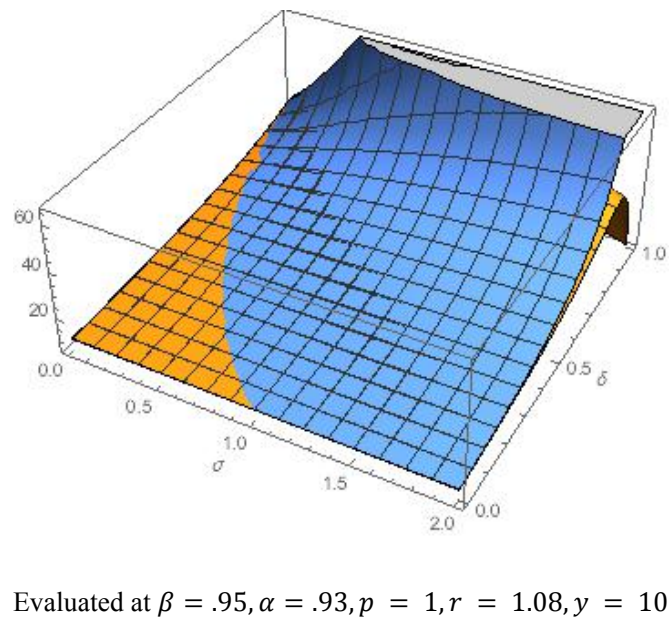

The figure graphs consumption in the first period under a STH (in orange, when $\alpha<1$ ) and under the baseline case (in blue, when $\alpha=1$ ) as a function of IES (x-axis) and the depreciation rate (y-axis). We clearly see that there exists a region corresponding to low-values of both $\sigma$ and $\delta$ where consumption before the STH is greater than during the baseline case.

The regions for the parameters $\sigma$ and $\delta$ for which consumption increases in the period before a STH make sense. These are the circumstances in which the wealth effect of the STH dominates and consumers use the gains from lower prices during the STH to increase consumption in the period before. This is more likely to be the case if there is low depreciation and the consumption in period 1 will have a larger spillover into period 2 or if there is a low IES and they have less of an incentive to shift consumption across periods.

\section{Further Findings}

In the paper we restrict our analysis to spending at apparel, school supply and computer merchants. In Table A1, we present results for the remainder of the merchant groups detailed in Table 4. In particular, we show the effects of having any STH on spending at big box retailers, appliance stores and other non-apparel merchants. Some of the items at these stores, in particular at big box retailers, are temporarily exempt during STHs. We find a statistically significant and economically large (22.9\%) increase at big box retailers and no change in the other categories. We do not find any evidence that consumers substitute away from other consumption by spending less at other non-apparel merchants and during the STH. 


\section{Additional Robustness Checks}

Having used numerous specifications to control for unobserved, state specific demand shocks that may be correlated with the timing of a STH, in this section we provide one last test to see whether this may be an issue. Using the Diary data, we perform the following counterfactual experiment. Focusing on the years before the first STH in New York, we analyse how individuals in a state behave on days that would eventually have an STH in their state. We label these counterfactual STHs "placebo STHs." This experiment is valid if we assume that the timing of state-specific demand shocks is invariant across years. Finding that households in a state increased consumption on days that in later years would have a STH would be indicative of unobserved demand shocks influencing the decision to purchase, providing suggestive evidence that our main findings may be biased.

The main challenge of this approach is determining exactly when to assign the placebo STH. STHs are not on the exact same calendar date in a state each year but rather vary slightly year to year. We generate placebo STHs by taking the most recent sales tax in our data for each state listed in Table 1 and project it backwards based on the month, day of week and week of month when it began and its duration. This is consistent with the enacting legislation in many states which specify the timing of holidays in this manner. For example, in 2011 Connecticut had a tax holiday from Sunday August 21- Saturday August 27. Using our assignment rule, we simulate a holiday for Connecticut from Sunday August 18-Saturday August 24, 1996. Connecticut legislation (Conn. Gen. Stat §12-407e) states that the STH will start on the third Sunday in August and last a week. We test the effects of these placebo STHs on consumption for the period 1994-1996. We are restricted to these dates because state identifiers are first introduced in the public use CEX in 1994 and the first STH occurred in 1997.

Table A2 summarizes the results of running model (1) on the placebo STHs. In column 1, we find that there is no statistically significant increase in apparel consumption on days that would later have a STH. The same findings hold when distinguishing between women's, men's, and children's apparel. The coefficient on children's apparel is actually negative and statistically significant; however, after including household fixed effects, the finding disappears.

The result of this experiment further supports that our main findings are indeed driven by the temporary suspension of sales taxes during STHs and not by the heterogeneity of seasonal demand across different states. In those instances where the coefficient on the actual STH shows a statistically significant increase in consumption, the regressions using the placebo STHs show no corresponding positive significant response. In fact, one of our coefficients is negative and significant, which may indicate that STHs are placed during times when demand is relatively weak. 
Table A1: Spending Response to Sales Tax Holidays at Additional Merchants (Credit Card)

\begin{tabular}{c|lll} 
& $\begin{array}{l}\text { Big Box } \\
(1)\end{array}$ & $\begin{array}{l}\text { Appliances } \\
(2)\end{array}$ & $\begin{array}{l}\text { Other Non Apparel } \\
(3)\end{array}$ \\
\hline \hline STH Any & $\begin{array}{l}0.275 \\
(0.062)\end{array}$ & $\begin{array}{l}-0.039 \\
(0.085)\end{array}$ & $\begin{array}{l}0.496 \\
(0.375)\end{array}$ \\
& & & \\
Effect $(\%)$ & 23.9 & -6.0 & 3.7 \\
N & $5,414,254$ & $5,414,254$ & $5,414,254$ \\
Adj R2 & 0.001 & 0.000 & 0.002 \\
\hline
\end{tabular}

Notes: Data cover the time period from May-September 2003. Each column represents a separate regression where the dependent variable is spending at the merchant type listed in the column heading. All regressions include controls for age, age squared, income, income squared, FICO score, a co-applicant flag, state of residence and transaction date fixed effects. Standard errors are clustered by state. The Effect (\%) is defined as the STH coefficient estimate divided by the mean of the dependent variable.

Source: Authors' tabulations from proprietary credit card data.

Table A2: Robustness Check of Spending Response to Placebo Sales Tax Holidays

\begin{tabular}{l|lllll} 
& $\begin{array}{l}\text { All } \\
(1)\end{array}$ & $\begin{array}{l}\text { Women } \\
(2)\end{array}$ & $\begin{array}{l}\text { Men } \\
(3)\end{array}$ & $\begin{array}{l}\text { Child } \\
(4)\end{array}$ & $\begin{array}{l}\text { Child } \\
(5)\end{array}$ \\
\hline \hline STH & 1.834 & 3.307 & -0.718 & -0.754 & -0.084 \\
& $(2.824)$ & $(2.797)$ & $(0.453)$ & $(0.340)$ & $(0.596)$ \\
& & & & & \\
Fixed effects: & & & & & \\
State & $\mathrm{X}$ & $\mathrm{X}$ & $\mathrm{X}$ & $\mathrm{X}$ & $\mathrm{X}$ \\
Household FE & & & & & \\
& & & & & \\
$\mathrm{N}$ & 130,532 & 130,532 & 130,532 & 130,532 & 164,676 \\
Adj R2 & 0.01 & 0.006 & 0.005 & 0.01 & 0.037 \\
\hline
\end{tabular}

Notes: Each column represents a separate regression where the dependent variable is spending on the type of apparel listed in the column heading. Regressions (1)-(4) include controls for age, sex, and race of household head, household composition, income category. All regressions include calendar date fixed effects. Standard errors are clustered by state.

Source: Authors' tabulations from Consumer Expenditure Survey Diary, 1994-1996. 